\title{
Optimal Fungicide Application Timings for Disease Control Are Also an Effective Anti-Resistance Strategy: A Case Study for Zymoseptoria tritici (Mycosphaerella graminicola) on Wheat
}

\author{
F. van den Berg, F. van den Bosch, and N. D. Paveley
}

First and second authors: Department of Computational and Systems Biology, Rothamsted Research, Harpenden, Hertfordshire AL5 2JQ, UK; and third author: ADAS High Mowthorpe, Duggleby, Malton, North Yorkshire, YO17 8BP, UK. Accepted for publication 5 July 2013.

\begin{abstract}
van den Berg, F., van den Bosch, F., and Paveley, N. D. 2013. Optimal fungicide application timings for disease control are also an effective anti-resistance strategy: A case study for Zymoseptoria tritici (Mycosphaerella graminicola) on wheat. Phytopathology 103: 1209-1219.

Strategies to slow fungicide resistance evolution often advocate early "prophylactic" fungicide application and avoidance of "curative" treatments where possible. There is little evidence to support such guidance. Fungicide applications are usually timed to maximize the efficiency of disease control during the yield-forming period. This article reports mathematical modeling to explore whether earlier timings might be more beneficial for fungicide resistance management compared with the timings that are optimal for efficacy. There are two key timings for fungi-

disease control on the upper leaves of the crop canopy that are crucial to yield. A differential equation model was developed to track the dynamics of leaf emergence and senescence, epidemic growth, fungicide efficacy, and selection for a resistant strain. The model represented Zymoseptoria tritici on wheat treated twice at varying spray timings. At all fungicide doses tested, moving one or both of the two sprays earlier than the normal T1 and T2 timings reduced selection but also reduced efficacy. Despite these opposing effects, at a fungicide dose just sufficient to obtain effective control, the T1 and T2 timings optimized fungicide effective life (the number of years that effective control can be maintained). At a higher dose, earlier spray timings maximized effective life but caused some reduction in efficacy, whereas the $\mathrm{T} 1$ and $\mathrm{T} 2$ timings maximized efficacy but resulted in an effective life 1 year shorter than the maximum achievable.
\end{abstract} cide treatment of winter wheat in the United Kingdom: full emergence of leaf three (counting down the canopy) and full emergence of the flag leaf (leaf 1). These timings (referred to as $\mathrm{T} 1$ and $\mathrm{T} 2$, respectively) maximize
Additional keywords: healthy area duration, leaf blotch, selection ratio.
Guidance to growers on fungicide resistance management usually advocates that treatments should be applied earlier in epidemic development, rather than later. The specific wording used depends on the particular pathogen and fungicide mode of action to which the guidelines apply but the general principle is consistent. Examples include "SDHI [succinate dehydrogenase inhibitor] fungicides should be used preventively or at the early stage of disease development" (www.FRAC.info) and "Monitor crops regularly for disease and treat before infection becomes well established" (3).

Brent and Hollomon (5) pointed out that there was no underpinning experimental evidence for such assertions; a position confirmed subsequently at a workshop reported by Zlof and Sunley (41). However, Brent and Hollomon (5) described two hypotheses which could provide a rationale for such recommendations. The first relates specifically to where a systemic fungicide is mixed with a multi-site-acting "protectant" fungicide, which is only effective against spores arriving on the plant after treatment. When treatment is applied to existing infections, the systemic component is effectively acting alone and the anti-resistance benefit of the mixture (15) may be lost. The second, more widely applicable hypothesis compared waiting until a threshold population appears before treating against applying fungicide

Corresponding author: F. van den Berg;

E-mail address: femke.vandenberg@ rothamsted.ac.uk

http://dx.doi.org/10.1094/PHYTO-03-13-0061-R

(C) 2013 The American Phytopathological Society prophylactically to keep populations permanently low, the assertion being that the opportunity for selection could be lower with the latter approach. In this article, we use a modeling approach to develop and critically test the second hypothesis.

Some development of the hypothesis is required to define the processes to be modeled. There are two phases of fungicide resistance evolution, both of which could be affected by timing of treatment. During the initial emergence phase, the resistant strain has to arise through mutation and invasion. During the subsequent selection phase, the resistant strain is present in the pathogen population and the fraction of the pathogen population carrying the resistance increases due to the selection pressure caused by the fungicide (36).

During the emergence phase, the absolute number of mutant fungicide-resistant spores occurring per time unit in a fungal population is the product of the number of spores produced in the population per time unit and the mutation probability. Thus, population size is a key component in the number of fungicide resistance mutations occurring per time unit, suggesting that keeping population size low could be advantageous. However, there is a counteracting mechanism, because the mutant type has to build up a population in an environment occupied by the sensitive type. If the density of the sensitive type is higher, it is less likely that the mutant will increase greatly in numbers, because more of the host tissue is occupied by the sensitive type (36). Stochastic modeling approaches are being developed currently by the authors to address the effects of anti-resistance strategies on the emergence phase. This article focusses on the selection phase. 
The strength of selection is quantified as the rate of change in the proportion of the pathogen population consisting of the fungicide-resistant strain. Because selection is about change of proportions, it is inherently independent of population size. However, selection is driven by the rate of change of population size; specifically, by the difference in the relative growth rate $(r)$ of the sensitive and resistant populations. The work reported here tested the possibility that fungicide timing could affect selection through effects on epidemic dynamics rather than through population size per se.

We used the model reported by Hobbelen et al. (14) as a starting point for the work. That article describes a modeling analysis in which various fungicide mixture treatments were compared for their effect on selection when applied at fixed spray timings against Zymoseptoria tritici comb. nov. (Septoria tritici leaf blotch; previously known as Mycosphaerella graminicola) on winter wheat (Triticum aestivum). To allow a realistic representation of the effect of varying spray timing, two main changes were made to the model. The first change resulted from field experiments reported by Paveley et al. (28), which showed that changing spray timing has different effects on epidemic progress on each of the layers of culm leaves which form the wheat canopy. Hence, for example, for the uppermost leaf layer (the flag leaf), the highest dose efficiency (reduction in area under the disease progress curve caused by any given fungicide dose) is achieved by a spray timing close to or shortly after full flag leaf emergence. Spray applications prior to full emergence of that layer are less effective because they do not deposit directly onto the leaf surface. Spray timings later in leaf life are less effective because more of the infections on that leaf layer are either already infectious or are too far into their latent period to be prevented from becoming infectious. Furthermore, after the first spray application, any newly emerging leaf tissues are completely unprotected until the next spray application. This is likely to have

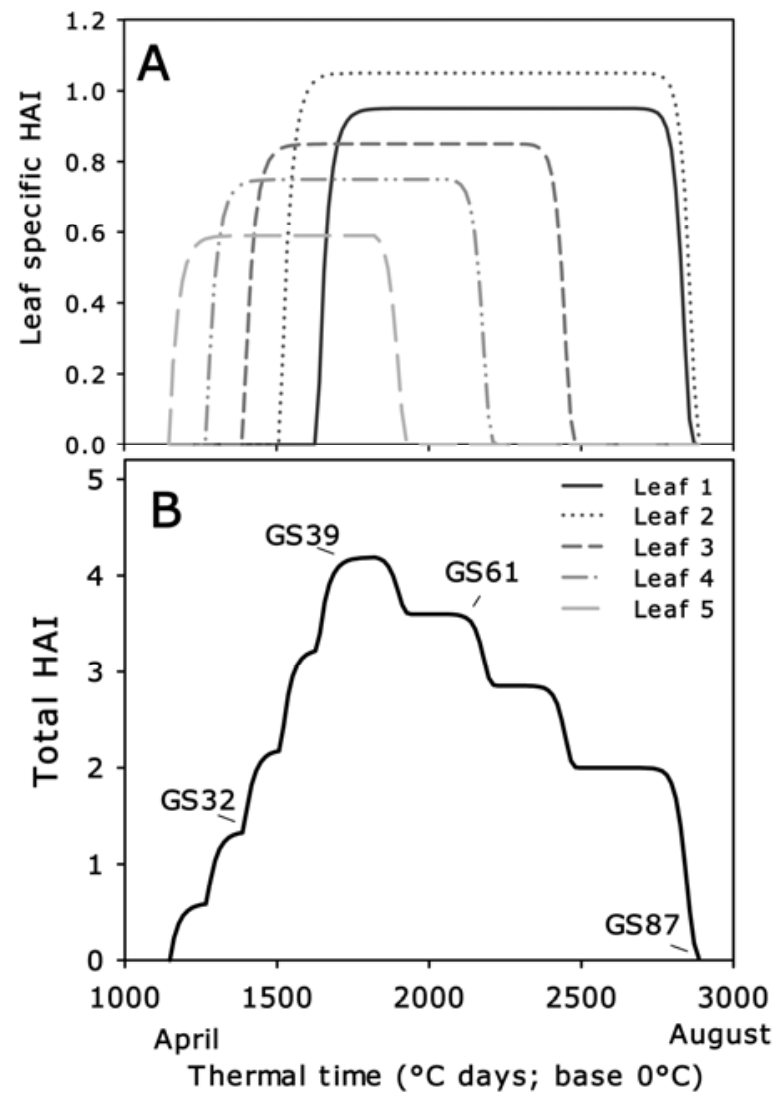

Fig. 1. Healthy area index (HAI) growth for $\mathbf{A}$, individual leaf layers and $\mathbf{B}$, the top five leaves combined in the absence of disease. large consequences for both disease control and selection. Therefore, when addressing spray timing-related questions, it seems important to model the area development for individual leaves. Therefore, leaf emergence and senescence and epidemic dynamics were represented for each leaf layer in the model described here in order to represent these treatment timing effects. The second change to the model was to subdivide the latent period into age classes, so that the effect of systemic fungicide application on latent infections could be constrained to those cohorts of lesions which were in the early part of their latent period at the time of application (27).

Fungicide treatment advice for the control of foliar pathogens of wheat in the United Kingdom centers around two key spray timings. The first treatment is applied when leaf 3 (counting down the canopy from the flag leaf [leaf 1]) is fully emerged (typically at approximately growth stage [GS] 32) (8) and the second when the flag leaf is fully emerged. These two treatments-termed T1 and $\mathrm{T} 2$, respectively, by crop managers-optimize dose efficiency for disease control on the upper three leaf layers of the crop canopy that are critical to yield formation (27).

Hence, a key question arises, which relates back to the original hypothesis from Brent and Hollomon (5): is it a good anti-resistance strategy to apply fungicide treatments earlier than might otherwise be dictated by the need to achieve the best dose efficiency? Here, we explore this question for the subset of possible treatment options where two treatments are applied and spray timings are varied from the normal $\mathrm{T} 1$ and $\mathrm{T} 2$ spray timings. Cases where additional treatments are applied (for example, adding an earlier treatment and, thus, also changing the number of applications) will be described elsewhere.

\section{THEORY AND APPROACHES}

Model development. A differential equation model was developed from the model reported by Hobbelen et al. (15), because this is currently the only fungicide resistance model that has been tested against field data. The crop canopy in that model was represented as a single unit. Here, we subdivide the canopy into leaf layers, following the approach developed by Audsley et al. (4) and Milne et al. $(24,25)$.

Crop growth. The decimal code system for measuring wheat development using the prefix GS, denoting the growth stage used in this article, is described by Chang et al. (8). The total leaf area index, $A$, of an individual leaf layer with leaf number $n$ is a function of thermal time $t$, and is described by a monomolecular equation (34), reaching a maximum value of $A_{\max \_n}$. Leaf growth results in an increase in the leaf's healthy area index (HAI) but is followed by a period of exponential decline due to leaf senescence, $\sigma_{n}(t)$, with a mean senescence rate, $s$, resulting in a decline in HAI. It is assumed that pathogen infection only affects HAI and not the growth and eventual size of the leaves and, therefore, it is essential to track the total area and HAI separately. In the absence of disease, the rate of change of the HAI of leaf $n, \dot{H}_{n}$, is thus given by

$$
\begin{aligned}
& \frac{d H_{n}}{d t}=\gamma\left(A_{\max \_n}-A_{n}\right)-\sigma_{n}(t) H_{n}
\end{aligned}
$$

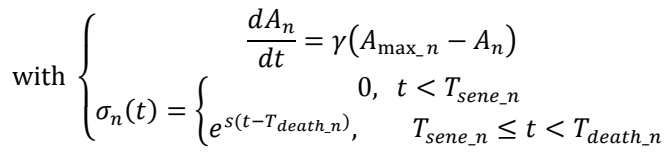

whereby $\gamma$ is the leaf expansion rate, leaves are counted downward from the flag leaf (leaf 1 ), and $T_{\text {sene } \_n}$ and $T_{\text {deat } \_n}$ are the time of senescence onset and leaf death, respectively, for leaf number $n$. A representation of leaf growth in the absence of disease is shown in Figure 1. 
For a fixed period of time, $T_{\text {extension_n }}$, after the onset of emergence of a new leaf, no stem extension takes place, which means that the newly emerging leaf remains at the same height as the previously fully emerged leaf layer. During this period of close proximity between the two leaf layers, close contact and dew runoff result in a relatively increased spore transfer (23). However, the emergence of culm leaves 1 to 4 occurs concurrently with stem extension, so that each newly emerged leaf grows away over the internode distance $h_{L}(4,23)$.

Disease dynamics. The Z tritici population modeled consists of two strains: strain $S$ is sensitive to the fungicide applied and strain $R$ is resistant to the fungicide. Infection by a pathogen spore results in a strain-specific latent leaf area, $L_{1 j}$, with $j=\{S, R\}$. The model includes multiple latent compartments, such that the rate of leaving the latent class is dependent on the time the lesion has already spent in it, resulting in a realistic distribution of the latent period (Fig. 2) (9). To ensure that the mean latent period matches the observed mean latent period of $Z$. tritici, $1 / \delta_{j}$, the transition rate within and between the latent compartments, $\delta_{j}$, is scaled by the total number of latent compartments, $m$ (Fig. 2) (9). Latent lesions of strain $j$ that leave the last latent compartment result in infectious leaf area, $\mathrm{I}_{j}$, which remains infectious for a period of $1 / \mu^{\circ} \mathrm{C}$ days. Z. tritici is a necrotrophic pathogen, which means that, when lesions become infectious, the leaf tissue is killed. Therefore, leaf senescence does not contribute to lesion death and infectious leaf area does not contribute to HAI.

For Z. tritici, the predominant initial source of inoculum initiating the epidemic consists of ascospores landing on the rosette leaves. The resultant lesions on the rosette leaves are subsequently the main source of inoculum for culm leaves 5 to 1 (30). Lesions on the rosette leaves stop sporulating at the end of their infectious period; therefore, the inoculum contribution from the rosette leaves relies on the availability of susceptible tissues. When the rosette leaves start to senesce, the inoculum contribution by the rosette leaves starts to decline. However, because lesions appear a latent period later and keep sporulating on dead tissues over the infectious period, the decline in the lesion density on the rosette leaves will only become apparent a latent period plus an infectious period after the onset of senescence of the rosette leaves. The inoculum contribution from the lower leaves to the epidemic on the top five leaves is thus modeled as

$$
\begin{aligned}
& X(t)=\left\{\begin{array}{c}
X_{0}, \quad t<T_{\text {inoc_decline }} \\
X_{0} e^{-\psi\left(t-T_{\text {inoc_decline })},\right.} \quad T_{\text {inoc_decline }} \leq t<T_{\text {inoc_death }}
\end{array}\right. \\
& \text { with } \psi=e^{\omega\left(t-T_{\text {inoc_death }}\right)}
\end{aligned}
$$

Here, $\omega$ represents the lesion loss rate and is assumed to be equal to the leaf senescence rate, $X_{0}$ is the average initial density of infectious lesions on the lower leaves, and $T_{\text {inoc_decline }}$ and $T_{\text {inoc_death }}$ are the times at which the inoculum density on the rosette leaves starts to decline and has been reduced to zero, respectively. Note that the spores on the rosette leaves are biologically the same as those on the upper leaves and have the same infection abilities but, because the lesions on the rosette leaves are the source of inoculum initiating the infection on the other leaf layers, they need to be tracked separately. However, the total inoculum pressure is determined by summing the sporulating lesion density on the rosette leaves and the sporulating lesion density on all the other plant leaves (see equation 5). Although substantial Z. tritici infection is common on the leaf lamina of wheat, substantial infection on stems and ears is rare and, hence, we ignore the stems and ears in this study.

At the start of a growing season, a fraction, $\theta$, of the external primary inoculum is resistant. The fraction of external primary inoculum that is resistant is assumed to be equal to the fraction of spores and, hence, the fraction of infectious lesion tissue that is resistant at the end of the previous growing season; that is

$$
\theta=\frac{\sum_{n=1}^{5} I_{R_{n}}^{-}}{\sum_{n=1}^{5} I_{S_{n}}^{-}+\sum_{n=1}^{5} I_{R_{n}}^{-}}
$$

where $I_{S n}^{-}$and $I_{R_{n}}^{-}$denote the infectious tissue densities at the end of the previous growing season. It is assumed that this translates to a fraction, $\theta$, of resistant infectious lesions on the lower leaves at the start of the growing season. In the first growing season, $\theta=\theta_{0}$.

The transmission of the pathogen is modeled by three terms: (i) compound parameter, $\rho$, which incorporates spore production, infection efficiency of the spores, and the probability that the spores stay within the crop canopy (the majority of spores are washed or blown out of the canopy or into the soil); (ii) probability $P_{h, n}$, that a spore originating from leaf $h$ reaches leaf $n$; and (iii) probability $H_{n} / A_{n}$, defining whether, when a spore lands on a leaf, it lands on a healthy site. The probability $P_{h, n}$ that spores reach a target leaf decreases exponentially with the distance of the inoculum source (29), whereby the distance between the source and target leaf, $\pi_{h, n}$, is calculated from the average height of the individual leaf layers such that

$$
P_{h, n}= \begin{cases}e^{-\sigma_{\text {down }} \pi_{h, n},} & n<h \\ e^{-\sigma_{u p} \pi_{h, n},} & n \geq h\end{cases}
$$

and where $\sigma_{\text {down }}$ and $\sigma_{u p}$ are measures for the ease of downward and upward spread, respectively. A spore can only land at one location and, therefore, the sum of probabilities of landing at different leaves can never exceed 1 .

Thus, the leaf layer specific tissue dynamics can be summarized by

$$
\begin{aligned}
& \frac{d A_{n}}{d t}=\gamma\left(A_{\max _{n}}-A_{n}\right) \\
& \frac{d H_{n}}{d t}=\gamma\left(A_{\max _{n}}-A_{n}\right)-\rho_{S}\left(\frac{H_{n}}{A_{n}}\right)\left(P_{o, n}(1-\theta) X+\sum_{h=1}^{4} P_{h, n} I_{S_{h}}\right)- \\
& \quad \rho_{R}\left(\frac{H_{n}}{A_{n}}\right)\left(P_{o, n} \theta X+\sum_{h=1}^{4} P_{h, n} I_{R_{h}}\right)-\sigma_{n}(t) H_{n} \\
& \frac{d L_{1 S_{n}}}{d t}=\rho_{S}\left(\frac{H_{n}}{A_{n}}\right)\left(P_{o, n}(1-\theta) X+\sum_{h=1}^{4} P_{h, n} I_{S_{h}}\right)-m \delta_{S} L_{1 S_{n}}- \\
& \quad \sigma_{n}(t) L_{1 S_{n}} \\
& \frac{d L_{1 S_{n}}}{d t}=m \delta_{S} L_{(i-1) S_{n}}-m \delta_{S} L_{i S_{n}}-\sigma_{n}(t) L_{i S_{n}} \\
& \frac{d L_{1 R_{n}}}{d t}=\rho_{R}\left(\frac{H_{n}}{A_{n}}\right)\left(P_{o, n} \theta X+\sum_{h=1}^{4} P_{h, n} I_{R_{h}}\right)-m \delta_{R} L_{1 R_{n}}-\sigma_{n}(t) L_{1 R_{n}} \\
& \frac{d L_{i R_{n}}}{d t}=m \delta_{R} L_{(i-1) R_{n}}-m \delta_{R} L_{i R_{n}}-\sigma_{n}(t) L_{i R_{n}} \quad(2 \leq i \leq m) \\
& \frac{d I_{S_{n}}}{d t}=m \delta_{S} L_{m S_{n}}-\mu I_{S_{n}} \\
& \frac{d I_{R_{n}}}{d t}=m \delta_{R} L_{m R_{n}}-\mu I_{R_{n}}
\end{aligned}
$$

A schematic overview of the disease dynamics on a single leaf layer is shown in Figure 3 and an example of the predicted disease dynamics on leaves 1 to 4 , compared against observed disease dynamics, is shown in Figure 4.

Fungicide dynamics. Fungicide effects were parameterized to represent the quinone outside inhibitor (QoI) pyraclostrobin 
(BASF), which has both protectant and eradicant action. The protectant effect is modeled by a proportional reduction in the infection efficiency, which can be modeled by a reduction in compound parameter $\rho_{j}$, and the eradicant effect is modeled by a proportional increase in the latent period, $1 / \delta_{j}$. However, the eradicant action of systemic fungicides is generally only effective during the early part of the latent phase $(27,28)$ and, hence, we assume that only lesions that are in the first half of their latent period are affected by the eradicant action of the fungicide. The proportional changes in latent period and the compound parameter due to the application of a fungicide are calculated every degree-day for each leaf layer according to the fungicide's dose response curves, leading to

$$
\begin{gathered}
\rho_{j}(t)=\rho\left(1-\alpha_{\rho, \max }\left(1-e^{-\kappa_{\rho_{j}} d(t)}\right)\right) \\
\delta_{j}(t)= \begin{cases}\delta\left(1-\alpha_{\delta, \max }\left(1-e^{-\kappa_{\delta_{j}} d(t)}\right)\right), & \text { in } \dot{L}_{i} \text { with } i \leq m / 2 \\
\delta, & \text { in } \dot{L}_{i} \text { with } i \leq m / 2\end{cases}
\end{gathered}
$$

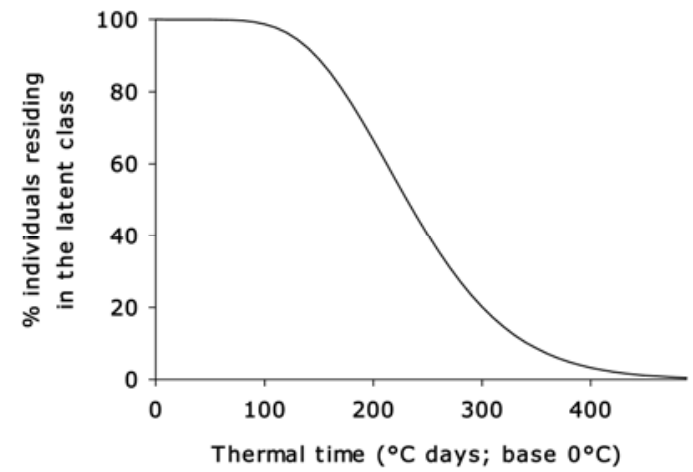

Fig. 2. Percentage of pathogen individuals that still reside in the latent class as a function of time. Mean latent period is 244 degree-days, with a standard deviation of 77 degree-days, whereby individuals enter the first latent compartment at $t=0$. with $\alpha_{\rho \max }$ and $\alpha_{\delta \max }$ as the maximum reduction in the target parameter, $\kappa_{\mathrm{p} j}$ and $\kappa_{\delta j}$ as the shape parameters of the dose response curves for strain $j$, and $d(t)$ as the effective daily fungicide dose.

By analogy with Milne et al. (25), the fungicide dose $D_{n}$ arriving at leaf $n$ depends on total dose sprayed, $D_{0}$, the probability of being intercepted by leaf $n$, and the probability of not being intercepted by any of the leaves above leaf $n$, such that

$$
D_{n}=D_{0}\left(1-e^{-\tau A_{n}\left(t_{\text {spray }}\right)}\right) e^{-\tau \sum_{j=1}^{n-1} A_{j}\left(t_{\text {spray }}\right)}
$$

whereby $\tau$ is a measure for the average projection area of the leaves and stem onto a horizontal surface. From the time of application, the applied active substance of the fungicide will decay over time, resulting in an effective daily dose concentration $d(t)$ on leaf $n$ of

$$
d(t)=\frac{D_{n}}{A_{n}} e^{-v\left(t-t_{\text {spray }}\right)}
$$

with $v$ as the decay rate of the active substance. It is assumed that the fungicide also affects the susceptible population on the rosette leaves, whereby the reduction of the susceptible population due to a spray application is directly related to the dose of the fungicide, and the density of the susceptible population recovers according to the decay rate of the fungicide. It is further assumed that the effect of the spray event on the actual density of the infectious lesions on the rosette leaves is delayed by a latent period. This is modeled by

$$
X(t)=\left\{\begin{array}{c}
(1-\eta) X_{0}\left(1-\alpha_{X, \max }\left(1-e^{-k_{X} d\left(t-\frac{1}{\delta}\right)}\right)\right)+\eta X_{0}, \quad t<T_{\text {inoc_decline }} \\
(1-\eta) X_{0}\left(1-\alpha_{X, \text { max }}\left(1-e^{-k_{X} d\left(t-\frac{1}{\delta}\right)}\right)\right) e^{-\psi\left(t-T_{\text {inoc_decline }}\right)} \\
+\eta X_{0} e^{-\psi\left(t-T_{\text {inoc_decline })},\right.}, T_{\text {inoc_decline }} \leq t<T_{\text {inoc_death }}
\end{array}\right.
$$

where $\eta$ is the fraction of infectious lesions on the rosette leaves that is of the resistant strain (note: at the start of the growing

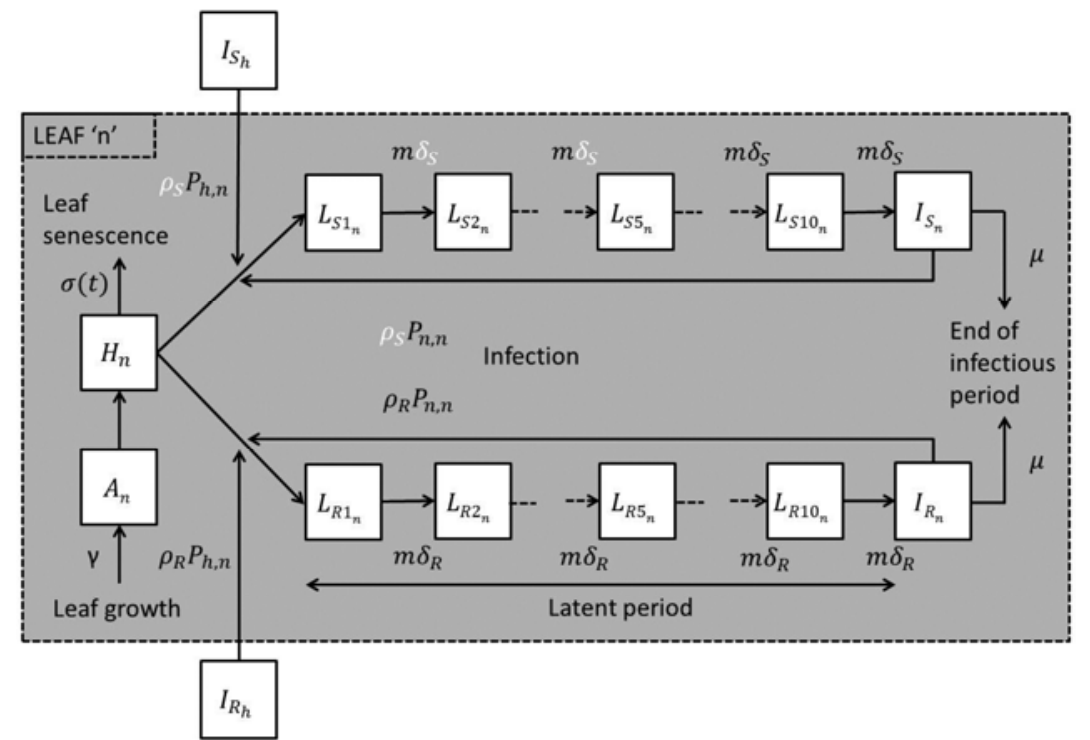

Fig. 3. Schematic overview of the dynamics for leaf "n". Leaf growth at rate $\gamma$ results in both an increased leaf size, $A_{n}$, and an increased healthy area index (HAI), $H_{n}$, whereas senescence at rate $\sigma(t)$ results in a decreased HAI. Infection by spores of the sensitive and resistant pathogen strain results in latent tissues, $L_{S}$ and $L_{R}$, respectively, which after an average latent period of $1 / \mathrm{m} \delta_{S}$ and $1 / \mathrm{m} \delta_{R}$ result in sporulating tissues $I_{S}$ and $I_{R}$, which continue to sporulate over their infectious period of $1 / \mu$. Infections occur with a transmission rate that depends on (i) compound parameter, $\rho$, which incorporates spore production, infection efficiency of the spores, and the probability that the spores stay within the crop canopy; (ii) probability $P_{h, n}$ that a spore originating from leaf $h$ reaches leaf $n$ (whereby $P_{n, n}$ represents internal infection); and (iii) probability $H_{n} / A_{n}$, defining whether, when a spore lands on a leaf, it lands on a healthy site. Parameters that are affected by the fungicide applications are presented in white. Note that the fungicide only affects the first half of the latent period of the sensitive strain. 
season, $\eta=\theta$ ), $\alpha_{X, \max }$ is the maximum density reduction of the susceptible inoculum on the rosette leaves due to a spray event, and $k_{X}$ is the dose-response parameter for the rosette leaves.

Spraying the lower leaves results in a temporary decline of the susceptible population on these leaves, which causes an increase in the fraction of resistance of the inoculum from the rosette leaves. Note that, because $X(t)$ represents the infectious lesions on the rosette leaves, the effect that spray applications at time $t_{s}$ has on $X(t)$ and, hence, $\eta$ is only evident a latent period after the spray application (i.e., at time $t_{s}+\delta$ ). The new fraction can be calculated from

$$
\eta\left(t_{s}^{+}+1 / \delta\right)=\frac{\eta\left(t_{s}^{-}+1 / \delta\right) X\left(t_{s}^{-}+1 / \delta\right)}{\left(1-\eta\left(t_{s}^{-}+1 / \delta\right)\right) X\left(t_{s}^{-}+1 / \delta\right)\left(1-\alpha_{X, \max }\left(1-e^{-k_{x} d\left(t_{s}\right)}\right)\right)+\eta\left(t_{s}^{-}+1 / \delta\right) X\left(t_{s}^{-}+1 / \delta\right)}
$$

where superscripts - and + refer to an infinitesimal small time step before or after the time of the spray application, respectively. The fraction of resistance then remains constant until the next spray event.

Measure of success of resistance management. As outlined in the review by van den Bosch and Gilligan (35), the criteria used to evaluate a fungicide resistance strategy can affect model predictions and, thus, has to be chosen with care. Although an evaluation criterion such as the takeover time (time from introduction of the fungicide until the fraction of the pathogen population that is resistant to the fungicide has exceeded a threshold value) has the advantage of often being directly measured in fungicide resistance experiments, it is not related to yield. However, the primary objective of using fungicides is to maintain yield. Therefore, we use an evaluation criterion which takes into account both selection for fungicide resistance and yield. This evaluation criterion is referred to as the fungicide's effective life, and is defined as the number of consecutive growing seasons that the fungicide is able to keep the disease-induced healthy area duration (HAD) (37) loss below a predefined threshold value, representing effective control. The healthy area is defined as the green leaf area available for photosynthesis. For Z. tritici, the healthy area includes tissues containing latent lesions. The HAD is calculated as the total area under the healthy and latent leaf area index curves for leaves 1 to 3 during the grain filling period (i.e., $t=$ [2150 to 2900] because the HAD for leaves 1 to 3 during grain filling is related to the achieved winter-wheat yield) $(7,37)$. The HAD loss is then calculated as the difference between the HAD for leaves 1 to 3 during the grain filling period (i.e., $t=[2150$ to 2900] in the absence and presence of disease). The threshold HAD loss was set at $5 \%$.

The selection ratio is calculated each year, where the selection ratio is defined as the proportional increase in the frequency of the resistant strain on the top five leaves during one full growing season.

Parameter estimation and model testing. The parameters used in the model describe wheat plants and pathogen epidemics under standard U.K. conditions (temperature, light, water, and nutrients). Under field conditions, certain key wheat development stages, such as leaf emergence and anthesis, have been shown to be closely related to the cumulative growing degree-days (the cumulative average temperature [in ${ }^{\circ} \mathrm{C}$ ] of each day over a time period) the plant has experienced $(2,38)$. The disease dynamics closely follow the host dynamics, with marked increases in growth at higher temperatures $(2,26)$, and spray timings are often described in terms of these clearly defined crop development stages. Hence, we model all dynamics in degree-days, whereby daily measurements were converted to degree-day measurements by adopting a base temperature of $0^{\circ} \mathrm{C}$ and the growing season average temperature at Cambridge in the United Kingdom (which represents a major wheat-growing region) during 1984 to 2003 of $15.2^{\circ} \mathrm{C}$ (Met Office, United Kingdom) (i.e., one calendar day equals 15.2 degree-day). The model parameters and the estimates of their values are summarized in Tables 1 and 2.

Crop parameters. Wheat leaves emerge a phyllochron apart, whereby a phyllochron $(P)$ is 122 degree-days long (2). Published data on leaf emergence often refer to full leaf emergence rather than the onset of emergence (2), which is the measure used in the

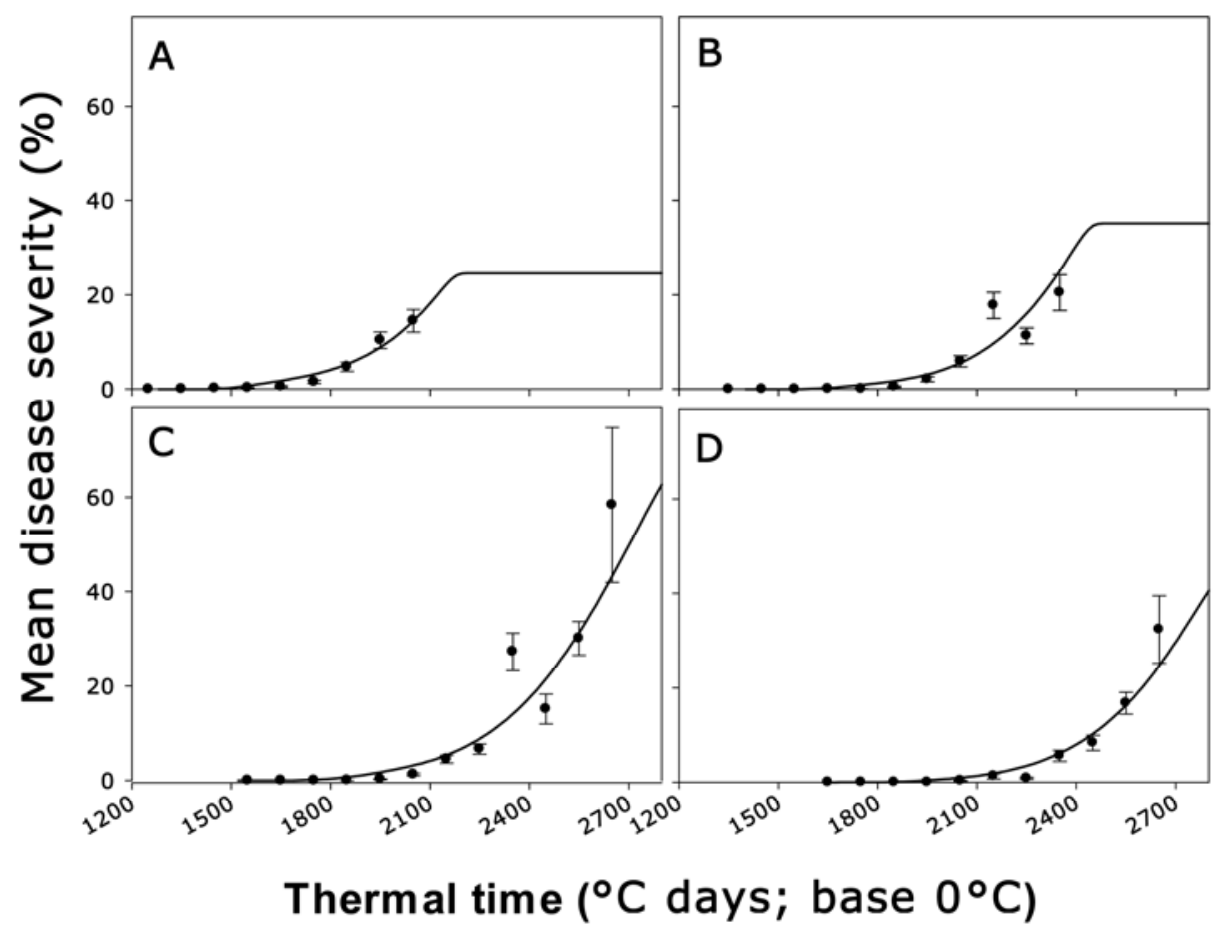

Fig. 4. Leaf layer specific disease progress curves for Septoria tritici leaf blotch. A to D, Leaves 4 to 1, respectively. Individual points represent the disease severity (percentage), averaged over all data points within a 100-degree-day interval, with their associated standard errors (33) (see main text for further details). An observation of leaf 3 emergence was used to ensure that the canopy emergence was similar for all individual epidemics. Lines represent the epidemic progress in percentage disease severity as estimated by the model for the default parameters, as presented in Table 2 . 
model simulations. Milne et al. (24) derived the time between the start of leaf emergence and full emergence as $2 \ln (3) / \gamma$, with $\gamma$ the constant leaf growth rate of 0.034 degree-days $^{-1}$. Given that the flag leaf has fully emerged at GS39 (i.e., $T_{e m_{-} 1}=1,700$ ) (2), both the onset and full emergence of the other leaves can then be calculated (Table 1).

The full emergence of the flag leaf at GS39 occurs $3 P$ before anthesis at GS61 $(6,17)$. At anthesis, all leaves have emerged and contribute $85 \%$ of the plant's maximum total green area index, leading to a maximum HAI of 5.9 (2). Leaves 1 to 5 have a total HAI of 4.2, leaving a HAI of 1.7 for leaves 6 and below. The leaflayer-specific maximum HAIs, $A_{\max \_n}$, are subsequently calculated according to the leaf's average actual size (24), resulting in HAIs of 0.59 to 1.05 (Table 1 ).

The lag period between full leaf emergence and the onset of senescence is said to vary between $4 P$ and $9 P$ and to depend on leaf size (20). Assuming that the largest leaf (leaf 2) has a lag period of $9 P$ (i.e., 1,098 degree-days), the onset of necrosis of leaf 2 is found to occur at $t=2,676$ degree-days. The lag periods and, hence, the onset of necrosis of the other leaves can be calculated according to their maximum HAI, leading to lag periods of $8 P$, $9 P, 7 P, 6 P, 5 P$, and $4 P$ for leaves 1 to 6 , respectively.
Senescence is assumed to occur with a mean rate, $s$, which was found to be $s=0.05$ by Milne et al. (24), with leaf death occurring $\approx 2,897,2,900,2,508,2,240,1,959$, and 1,678 degreedays for leaves 1 to 6 , respectively. This closely matches the observation that, at the end of grain filling (GS87), senescence is complete and all leaves have died (i.e., $T_{G S 87}=2,900 \approx T_{\text {death_1 }}$ ) (2). A representation of leaf growth in the absence of disease is given in Figure 1.

It is assumed that new leaves (leaves 1 to 4 only) remain at the same height as the previously emerged leaf until it is fully emerged itself, after which it moves away as a result of stem extension at a rate of $1 \mathrm{~cm}$ per 10 degree-days until it reaches its maximum height, which is located $10 \mathrm{~cm}$ above the previously emerged leaf layer (4). This leads to a total stem extension period, $T_{\text {extension }}$, of 100 degree-days and an internode height, $h_{L}$, of $10 \mathrm{~cm}$.

Disease parameters. Hobbelen et al. (15) estimated the initial area index for the infectious lesions on the rosette leaves (leaves 6 and below) to be $X_{0}=0.011$. When the rosette leaves start to senesce, the inoculum contribution by the rosette leaves will start to decline. However, because lesions appear a latent period later and keep sporulating on dead tissues over the infectious period,

TABLE 1 . Summary of the leaf layer specific crop growth parameters ${ }^{\mathrm{a}}$

\begin{tabular}{|c|c|c|c|c|c|}
\hline Leaf number $(n)$ & $\begin{array}{c}\text { Onset of leaf } \\
\text { emergence }\left(T_{\text {ini_n }}\right)\end{array}$ & $\begin{array}{c}\text { Leaf fully } \\
\text { emerged }\left(T_{e m \_n}\right)\end{array}$ & $\begin{array}{c}\text { Senescence } \\
\text { onset }\left(T_{\text {sene_n }}\right)\end{array}$ & $\begin{array}{l}\text { Leaf death } \\
\left(T_{\text {death_n }}\right)\end{array}$ & $\begin{array}{c}\text { Maximum } \\
\operatorname{GAI}\left(A_{\max _{n} n}\right)\end{array}$ \\
\hline 1 & 1,635 & 1,700 (GS39) & 2,676 & $2,897(\approx \mathrm{GS} 87)$ & 0.95 \\
\hline 2 & 1,513 & 1,578 & 2,676 & 2,900 (GS87) & 1.05 \\
\hline 4 & 1,269 & 1,334 & 2,066 (GS61) & 2,240 & 0.75 \\
\hline 5 & 1,147 & 1,212 & 1,822 & 1,959 & 0.59 \\
\hline $\mathrm{X}$ & $(1,025)$ & $(1,090)$ & $(1,578)$ & $(1,678)$ & $1.70(0.43)$ \\
\hline
\end{tabular}

a All timings are given in degree-days whereas the green area index (GAI) has dimensionless index units of square meters of leaf area per square meters of ground area. GS = growth stage. Leaves are counted downward from the flag leaf (leaf 1); leaf $X=$ leaf 6 and below.

TABLE 2. Summary of the leaf layer independent model parameters ${ }^{\mathrm{a}}$

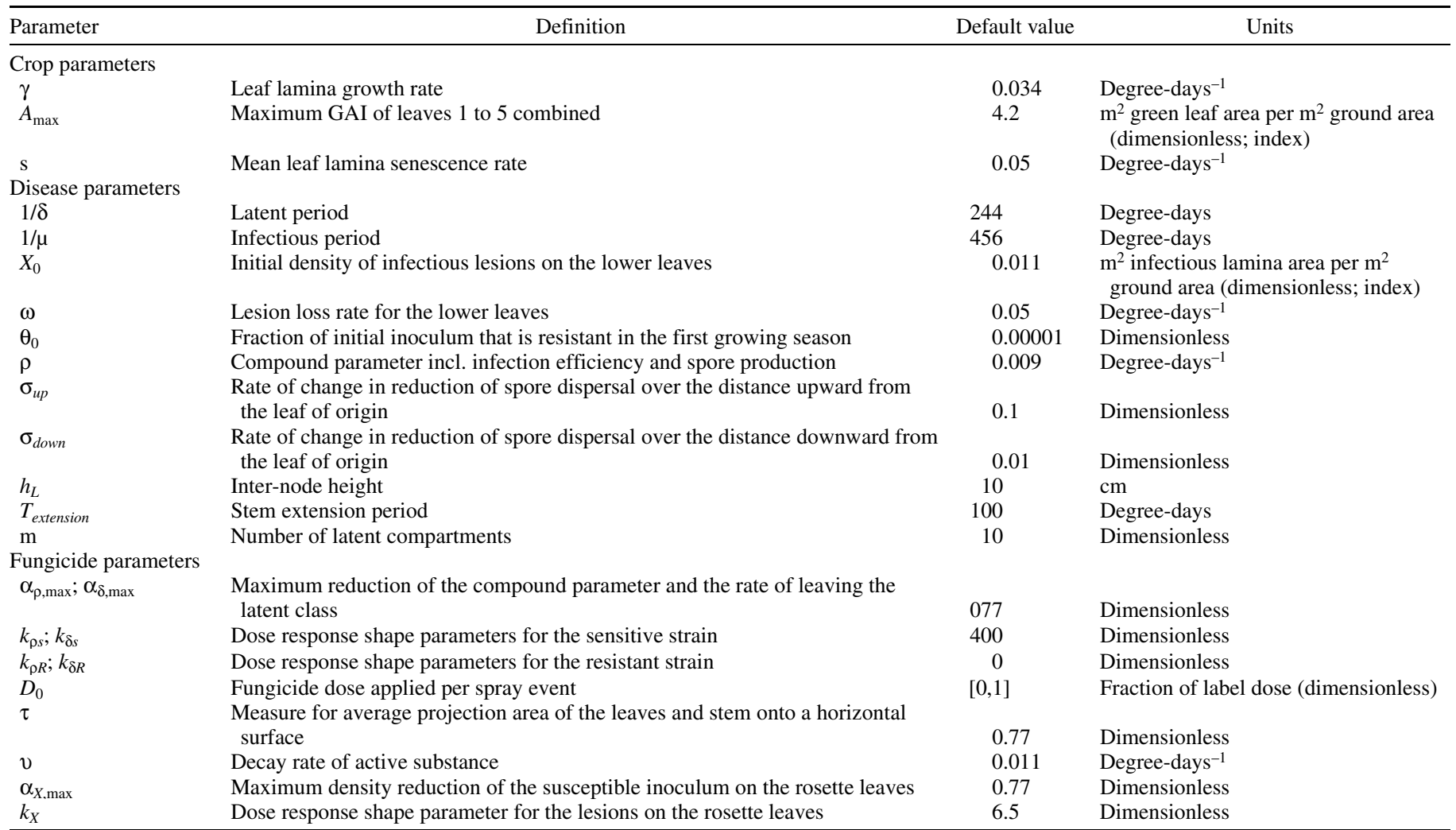

a All timings and rates, represented by $t$, are given in degree-days. GAI = green area index. The phrase "lower leaves: refers to the leaf 6 and below, situated in the canopy below the leaves that are modeled separately. For detailed parameter derivation and literature sources, please refer to the main text. 
the decline in the lesion density on the rosette leaves will only become apparent a latent period plus an infectious period after the onset of senescence of the rosette leaves (i.e., $T_{\text {inoculum_decline }}=$ $T_{\text {sene_6 }}+1 / \delta_{j}+1 / \mu=2,278$ degree-days (2). Assuming an average leaf senescence rate similar to the upper leaves, i.e. 0.05 degreedays $^{-1}$, the rate with which the area of infectious lesions on the lower leaves decreases is given by $\omega=0.05$, leading to $T_{\text {inoculum_death }}=2,378$ degree-days.

Under outdoor conditions and at an average temperature of $15.2^{\circ} \mathrm{C}$, the latent period of $\mathrm{Z}$. tritici was found to be roughly equal to 2 phyllochrons (i.e., 244 degree-days) (22). The infectious period of the lesions can be derived from the experiments performed by Eyal (10) and was found to be 30 days (i.e., 456 degree-days). Shaw (29) showed that, for natural rainfall events, the rate at which splash coverage declined with height was approximately -0.1 , leading to $\sigma_{u p}=0.1$.

There is no published information regarding compound parameter, $\rho$; the relative ease of downward spread, $\sigma_{\text {down }}$; and the number of latent compartments, $m$. Cuniffe et al. (9) showed that splitting the latent period into 10 compartments results in a smooth and realistic distribution of the latent period; hence, we chose $m=10$. The remaining two parameters were estimated by visually fitting the disease dynamics on the top three leaves to data observed on 'Riband' as presented by Audsley et al. (4), under the assumption that dispersal in rain droplets is more efficient downward than upward (i.e., $\sigma_{\text {down }}<\sigma_{u p}$ ). During this fitting process, all parameters were kept to their default values while $\rho$ was altered for a range of $\sigma_{\text {down }}$ values, after which the combination resulting in the model tracking the epidemic progress across the top three leaf layer in the most consistent manner was determined, leading to $\sigma_{\text {down }}$ and $\rho=0.007$. The article by Audsley et al. (4) provides a relatively high number of disease severity observations for each of the top three leaves, which means that the model dynamics for an individual epidemic can be fitted relatively accurately and ensures that the epidemic tracks across the subsequent leaves in an appropriate manner. However, this case represents a relatively mild epidemic and, thus, we adjust compound $\rho$, which represent the strength of the epidemic, according to a larger data set of disease severity observations (33), such that the modeled leaf layer specific severities represent an intermediate epidemic (Fig. 4). This data set contained leaf layer specific disease severity observations for 24 site/year/cultivar combinations, including seven sites, 10 susceptible cultivars with Septoria leaf blotch resistance ratings $\leq 5$, and four experimental years. Epidemics with a maximum disease severity $\leq 5 \%$

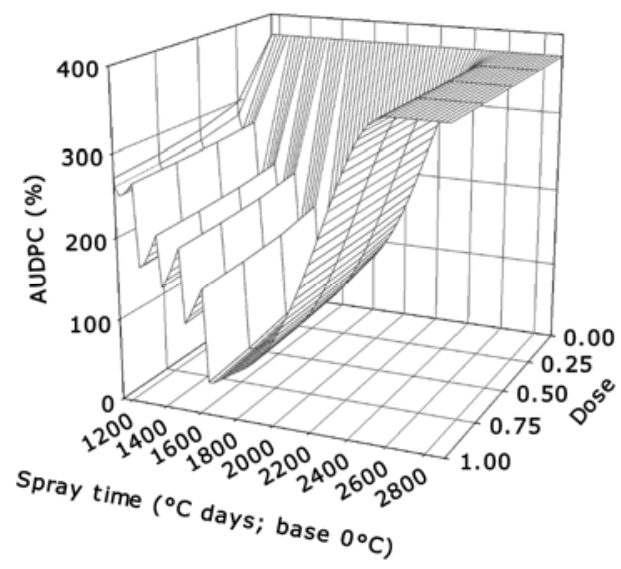

Fig. 5. Effect of spray timing on area under the disease progress curve (AUDPC) on the flag leaf as predicted by the model for different spray doses and timings. The dose is presented as a fraction of the label dose and the AUDPC is calculated as the percent leaf area affected by infectious and dead lesions accumulated from the onset of flag leaf emergence until the onset of flag leaf senescence. were excluded from the analysis and average disease severities were calculated over 100 degree-day intervals, with observations of leaf 3 emergence (usually at $\approx \mathrm{GS} 32$ ) used to ensure that the canopy emergence was similar for all individual epidemics. During this second fitting process, all parameters except $\rho$ were kept at their default value, after which $\rho$ was varied until the leafspecific disease progress curves as estimated by the model tracked through the largest number of data points (within their standard error range). The resulting $\rho$ value of 0.009 was subsequently set as the default parameter values for all further simulations.

Fungicide parameters. The fungicide parameters were based on the QoI fungicide pyraclostrobin. The half-life of pyraclostrobin is 3 to 11 days $(11,12,40)$. To allow comparison with the work from Hobbelen et al. (13), the default half-life was set to 4.1 days, leading to a fungicide decay rate, $v$, of 0.011 degree-days $^{-1}$. Parameter $\tau$ represents the leaf inclination angle. For wheat, Hosoi et al. (16) reported a leaf angle of $\approx 50^{\circ}$, from which the average fractional projection area onto a horizontal surface can be calculated to be $\cos \left(40^{\circ}\right)$, leading to $\tau=0.77$. Although pyraclostrobin has been shown to have some effect on the resistant strain (19), for simplicity we assume that this effect is negligible and, therefore, the dose response curve parameters of the resistant strain (i.e., $k_{\rho R}$ and $k_{\delta R}$ ) are set to zero. The maximum density reduction of the susceptible lesions on the rosette leaves, $\alpha_{\max , \rho}$, and the dose-response parameter, $k_{X}$, were calculated directly from the dose-response curve parameter estimates provided by Lockley and Clark (21), leading to $\alpha_{X, \max }=0.77$ and $\kappa_{X}=6.5$. Assuming that the fungicide affects the upper leaves in the same manner as the rosette leaves, we assume that the maximum reduction in the latent period and compound parameter is proportionally equal to the maximum reduction in lesion density on the rosette leaves (i.e., $\alpha_{\max , \rho}=\alpha_{\max , \delta}=0.77$ ) $\alpha_{\max , \rho}=$ $\alpha_{\max , \delta}=0.77$. Lockley and Clark (21) found that pyraclostrobin is equally effective as a protectant or an eradicant with regards to the control of Septoria tritici leaf blotch, such that $k_{\rho S}=k_{\delta s}$. Traditionally, dose-response curves describe the relatkionship between the disease severity at a certain time after spraying and the applied fungicide dose (21). Therefore, these dose-response curves are different from those in our model, which describe the instantaneous relationship between fungicide dose and the parameter values of individual pathogen life-cycle components. Thus, it was essential to convert the traditional disease severity doseresponse curves into dose-response curves for pathogen life-cycle components. Hereto, we used data for Septoria blotch severities on leaves of winter wheat as a function of the fungicide dose, averaged across several sites and years in the United Kingdom and a number of wheat cultivars (21). Because pyraclostrobin only affects the sensitive strain, we only used dose-response data for the year 2001, when resistance against pyraclostrobin was at a

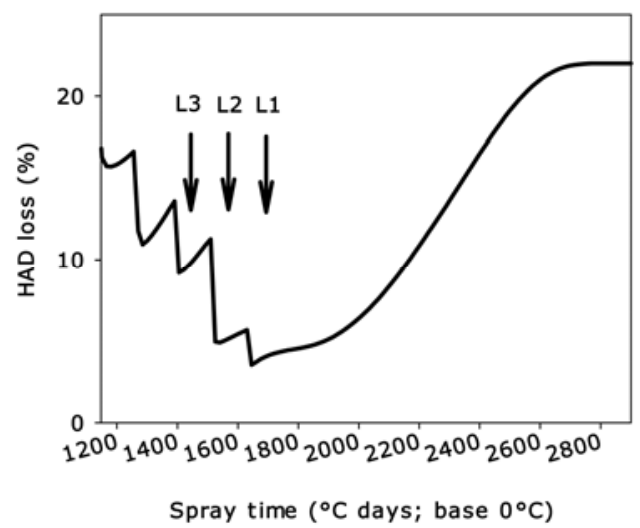

Fig. 6. Percent healthy area duration loss due to disease for the top three leaves of the canopy for different spray timings. Arrows represent the full emergence of leaves 3 to 1 , respectively. 
very low frequency. Disease severities were assessed on leaves 3 and 4 (or 1 and 2) 3 weeks (or 6 weeks) after a single spray at GS32. The average of these observed disease severities was used as an estimate of the disease severity on the upper leaves. The dose-response curve parameters of pryraclostrobin were then adjusted until the model's predicted average decrease in severity with an increased dose closely matched the field observations. Note that, in the model, we also assessed the disease severities on leaves 3 and 4 (or 1 and 2) 3 weeks (or 6 weeks) after a single spray at GS32. This led to the approximation $k_{\rho S}=k_{\delta S}=400$.

\section{RESULTS}

Disease progress and spray timings. The area under the disease progress curve dose-response versus spray timing surfaces for individual leaves as predicted by the model show the expected u-shaped pattern, revealing a clear optimal spray time window (Fig. 5) $(25,28,39)$. Moreover, Jarroudi et al. (18) suggest that the strongest risk to a crop occurs from infections arising between the emergence of leaf 2 and the flag leaf and roughly two latent periods before these leaves would naturally start to senesce. This would suggest that the loss of HAD for the upper three leaves has a minimum for spray timings between 1,578 and 2,188 degree days. The model prediction for the HAD loss of the top three leaves due to different spray timings confirms the finding of Jarroudi et al. (18) that the strongest risk occurs shortly after the full emergence of L2 and L1 (Fig. 6). This also suggests that the model can accurately represent the effect of varying dose and spray timings on the HAD of the crop.
HAD loss, selection, and effective life. First, consider the case of applying the fungicide twice at 0.3 times the label dose at timings relative to both the default T1 time $(t=1,456$ degreedays; T1 timing shift $=0$ days $)$ and the default T2 time $(t=1,700$ degree-days; T2 timing shift $=0$ days). When the $\mathrm{T} 1$ spray is applied earlier, this generally leads to reduced disease control on the upper three leaves and, when the T1 spray is brought forward by $>11$ days, disease control is insufficient, leading to the HAD loss threshold to be exceeded from the first growing season (Fig. 7D), resulting in an effective life of 0 years (Fig. 7A). The same is true when the T2 spray is applied $>10$ days earlier than its default timing. However, earlier T1 and T2 applications are also associated with a reduced selection ratio (Fig. 7G). The interplay between disease control and the selection ratio results in the highest effective life of 6 years being achieved by spray timing combinations around the default spray timings (Fig. 7A), which lead to HAD losses close to the predefined acceptable loss threshold and intermediate selection ratios (Fig. 7D and G).

These dynamics are affected by the total fungicide dose applied. At half or three-quarters of the label dose, the HAD losses on the upper three leaves are again smallest when both applications are later than the default timings (Fig. 7E and F) and the selection ratios are smallest when spray timings are brought forward from the default timings by $>11$ days (Fig. $7 \mathrm{H}$ and I). At higher doses, however, the optimal effective life values are shifted to earlier spray timings (Fig. 7B and C). The results suggest that, at higher doses, bringing forward the T1 spray by $>11$ days can increase the fungicide effective life by 1 year. A reduction in the fungicide dose applied at both spray applications also increases the
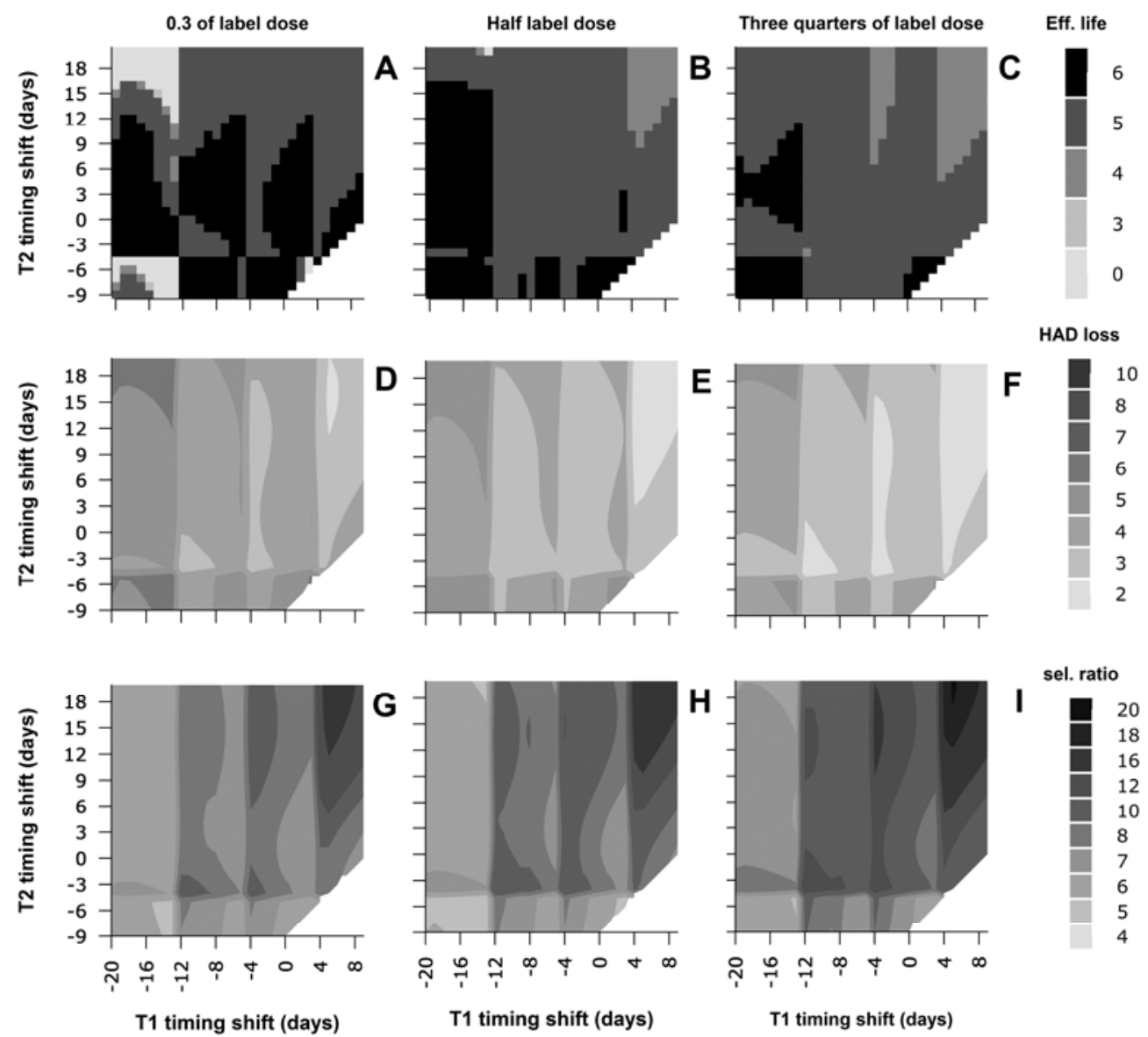

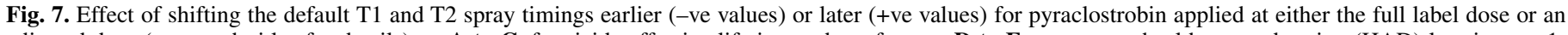

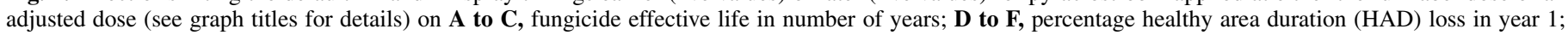

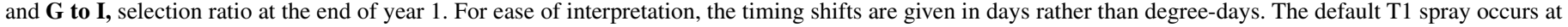

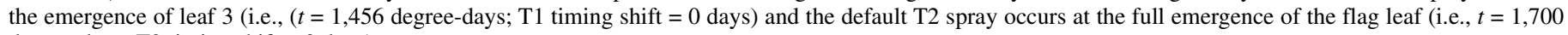
degree-days; T2 timing shift $=0$ days). 
range of spray timings over which the fungicide effective life is maximized.

The effects of changes in the balance of fungicide dose applied at each of the two sprays is described in Figure 8; however, in this case, with both applications at their default T1 and T2 timings. This figure clearly reveals that the optimal effective life is achieved for dose applications that are just sufficient to keep the HAD loss below the predefined threshold of $5 \%$. Spraying a lower dose leads to insufficient disease control from the first growing season and, hence, an effective life of 0 years, whereas spraying more than required leads to a rapid increase in the selection ratio, with a resulting decrease in effective life.

\section{DISCUSSION}

The current recommendation in the United Kingdom is to base fungicide programs around the T1 and T2 timings at the full emergence of leaf 3 (GS32) and the full emergence of the flag leaf (GS39). These timings generally optimize disease control $(1,27,28)$. However, treatment strategies that lead to increased disease control may have the associated disadvantage of increasing selection for fungicide resistance (36). This suggests that spray timings that optimize disease control might not optimize fungicide effective life. Despite spray timings that are good for disease control having an adverse effect on the selection ratio, we found that, providing that the applied fungicide dose is sufficient to keep the HAD loss just below the predefined threshold, the T1 and T2 timings optimize fungicide effective life and, therefore, represent an effective anti-resistance strategy. Our findings are discussed in detail in the next paragraphs.

Criteria to evaluate anti-resistance strategies have previously been based solely on minimizing the selection ratio (35). Early sprays generally resulted in a low selection ratio which, in accordance with the current resistance management guidance, suggests that early sprays are optimal from a resistance management point of view (3). However, earlier sprays were also associated with higher HAD losses on the upper leaves. As previously pointed out by van den Bosch and Gilligan (35), the fungicide's effective life and, hence, effective anti-resistance strategies are determined by the interplay between HAD loss and the selection ratio rather than the selection ratio alone.

Although the doses studied within this article lie within the range typically used in practice, the results show that only in the case of applying 0.3 times the label dose at both spray applications, which was sufficient to keep the HAD loss $<5 \%$, were the spray timings that were optimal for efficacy also optimal with respect to resistance management. When fungicides were applied at a higher dose, some additional disease control was achieved but at the cost of an increase in selection ratio. te Beest et al. (32) showed that it is economically rational to apply a higher fungicide dose than the dose required to minimize the total costs associated with disease (cost of fungicide inputs plus costs of diseaseinduced yield loss) in an average season. This is because of the uncertainty about future disease severity at the time of fungicide treatment decisions, and the high yield losses which result from fungicide treatment appropriate to an average season being applied in seasons when severe disease subsequently develops. Our analysis shows that the use of higher doses in order to be risk averse causes some reduction in effective life. In practice, this reduction may be the least-worst alternative, because applying the higher dose earlier to reduce selection results in reduced efficacy, thus defeating the purpose of applying a higher dose. Also, earlier "prophylactic" treatments may turn out to be unnecessary. Selection is largely independent of pathogen population size, whereas the economic benefit from treatment is dependent on population size. Hence, a prophylactic fungicide application which turns out to be not justified will have a deleterious effect on selection without a counteracting economic benefit.
Paveley et al. (28) showed that, for individual leaf layers, optimal disease control is achieved by sprays applied at or close to the full emergence of that leaf. Similar trends can be detected in our model study, which shows that optimal effective lives are also achieved by sprays applied at or close to the full emergence of an individual leaf. Thus, such spray timings appear to be in accordance with the resistance management advice that states that fungicides should be used in a preventive manner (3). However, care needs to be taken in interpreting what is intended by advocating "preventative" treatment and the avoidance of "curative" treatments. The distinction is reasonably clear for pathosystems where fungicides are applied before or during the arrival of initial inoculum (e.g., for the control of Phytophthora infestans late blight in potato) but less clear for winter-sown crops, where initial inoculum for most pathogens arrives in the autumn (by ascospores or from a "green bridge") but fungicide treatments do not commence until the following spring. In such cases, whenever a treatment is applied, it will be preventive on the cohort of lesions which result from infections occurring after treatment (most commonly on the leaf layer which has just emerged) but curative on the cohort of lesions which are in the latent phase at that time (most commonly on the leaf layer below that which has just emerged). Where the intention of the guidance is that treatments should be applied earlier rather than later, there can be a conflict with efficacy. In the case of winter wheat, control needs to be timed to protect the top three leaf layers in order to maximize interception of photosynthetically active radiation (PAR) by green
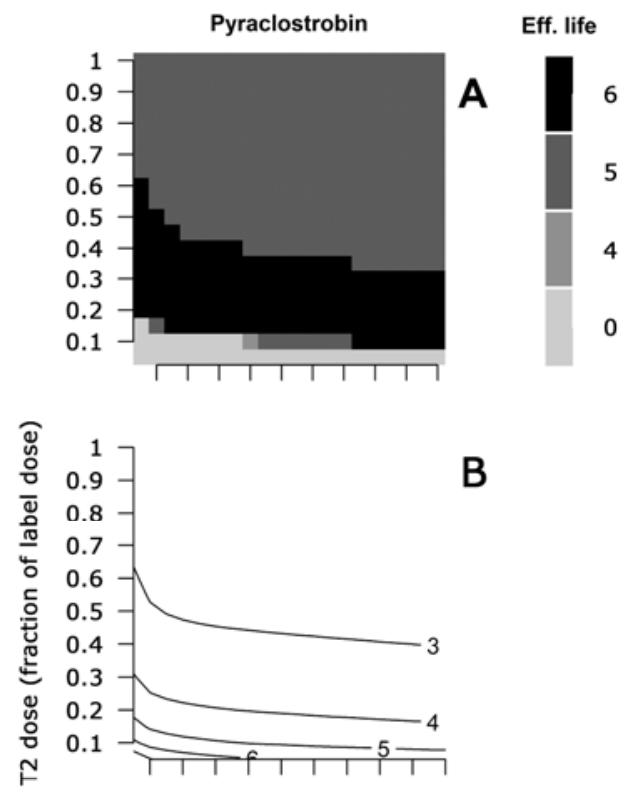

B

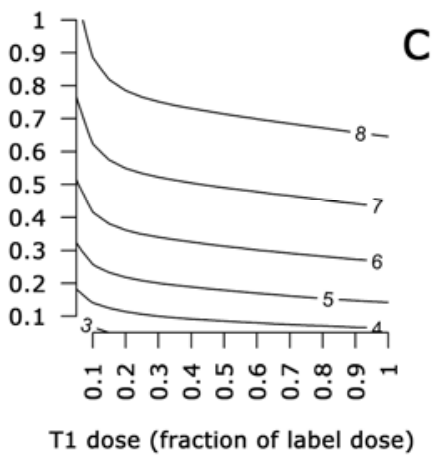

Fig. 8. Effect of $\mathrm{T} 1$ and $\mathrm{T} 2$ dose as a fraction of the label dose on $\mathbf{A}$, fungicide effective life; $\mathbf{B}$, healthy area duration (HAD) loss in year 1; and $\mathbf{C}$, selection ratio at the end of year 1 . Sprays are applied at the default T1 and T2 timings of 1,456 and 1,700 degree-days, respectively. 
lamina during grain filling (HGCA, 2008). Earlier timings shift the emphasis of control to earlier emerging leaves further down the canopy, which receive less PAR.

The associations between treatment effects and treatment timings are, to an extent, overemphasized in the model output, because the model assumes that all leaves within a given leaf layer are identical and emerge at the same time. In reality, there would be a population distribution of leaf emergence times. The inclusion of such variability would smooth both the accumulated healthy area curve and the relationship between HAD loss and spray timing. As a consequence, the slight valleys and ridges in the effective life results across a range of spray timings are unlikely to occur in reality. Although the inclusion of such variability might lead to minor quantitative changes, the conclusions are unlikely to be affected.

Differences in cultivars, fertilization levels, and so on can be represented by changes in individual (or a set of) crop growth parameters in the model. Such changes are likely to have a quantitative effect but the qualitative trends are likely to remain unchanged. Some of the epidemic parameters might also vary within and across seasons due to variability in a range of environmental factors such as rainfall. However, the fact that the model can accurately be extrapolated from a close fit to an individual epidemic to an average epidemic by changing suggests that the average qualitative results are likely to be unaffected by this variability. Further model runs also revealed that the main conclusions are not affected by changes to the fungicide parameters, such as $\tau, \alpha_{\max }, k_{\rho S}=k_{\delta S}, \alpha_{X, \max }$, and $k_{X}$ (results not shown). Finally, the current model assumes that the frequency of resistance does not change between seasons but, if there is a cost of resistance, this might affect the ability of the resistant spores to survive between seasons. The model can easily be extended to explore this possibility if such data were to become available. However, how the model results change for a completely different host-pathogen system is much harder to judge and should be tested in further model studies. For example, powdery mildew is, unlike Septoria, mainly spread by air, which results in a much more homogenous spore spread across the canopy, resulting in an increased disease pressure on the top leaves, an increased need for disease control on these leaves, and, hence, an increased selection for fungicide resistance.

In the model, lesions on the rosette leaves are assumed to be the predominant initial source of infection initiating the epidemic and, for simplicity, the leaf growth and epidemic dynamics of the rosette leaves were modeled with less biological realism than those of the upper five leaves. This might have affected the results and conclusions. In order to test the sensitivity of the findings to the modeling of the rosette leaves, we switched off the effect of fungicide applications on the lesion densities on the rosette leaves and, hence, on resistance selection on the rosette leaves (achieved by defining $\alpha_{X, \max }=0$ ). The results were qualitatively unchanged, suggesting that (i) the predominant selection occurs on the upper leaves that are targeted most effectively by fungicide treatment and (ii) a more complex form of representing leaf dynamics is probably unnecessary.

The initial fraction of resistance, $\theta_{0}$, was set to a low value (that would not be readily detectable by resistance monitoring in the field) to test the maximum beneficial effect that could be obtained by different resistance management strategies being implemented at or shortly after the introduction of a new mode of action. Increased initial fractions of resistance (as might result from resistance management commencing at a later stage) resulted in smaller benefits to effective life.

Our key conclusion from simulations of two-spray programs was that the T1 and T2 timings that optimize disease control also maximize the fungicide's effective life.. This does not necessarily mean that a two-spray program is optimal. In a following article, we will study the effective life of spray programs with different numbers of application. Although the results suggest that an increased fungicide use due to risk averseness is likely to lead to a reduction in effective life, the need to make alterations to spray application timings due to variability in weather conditions seems to be best dealt with under reduced-dose applications because reduced application doses go paired with an increased range of spray timings for which effective life is maximized. Given the economic losses due to fungicide resistance and the vast amount of resources invested in the development of new fungicides, the work presented in this study is of immediate practical relevance. However, to achieve a more complete overview over which control strategies are most sustainable, the methods described in this article could be merged with the methods described by te Beest et al. (31), which account for economic risk due to variability in disease severity, in future projects.

\section{ACKNOWLEDGMENTS}

Funding through the U.K. Chemicals Regulation Directorate of the Health and Safety Executive and Defra is gratefully acknowledged. Rothamsted Research receives support from the Biotechnology and Biological Sciences Research Council (BBSRC) of the United Kingdom.

\section{LITERATURE CITED}

1. Anonymous. 2008. Winter wheat disease control. Pages 1-8 in: Tech. Note TN607. SAC, Edinburgh.

2. Anonymous. 2008. Pages 1-32 in: The Wheat Growth Guide. HomeGrown Cereals Authority, London.

3. Anonymous. 2011. Pages 1-25 in: Fungicide Resistance Management in Cereals. Fungicide Resistance Action Group, Warwick, United Kingdom.

4. Audsley, E., Milne, A., and Paveley, N. D. 2005. A foliar disease model for use in wheat disease management decision support systems. Ann. Appl. Biol. 147:161-172.

5. Brent, K. J., and Hollomon, D. W. 2007. Fungicide resistance in crop pathogens: How can it be managed? FRAC Monogr. No. 1. FRAC, Bristol, UK.

6. Brooking, I. R., Jamieson, P. D., and Porter, J. R. 1995. The influence of daylength on final leaf number in spring wheat. Field Crops Res. 41:155165.

7. Bryson, R. J., Paveley, N. D., Clark, W. S., Sylvester-Bradley, R., and Scott, R. K. 1997. Use of in-field measurements to estimate the effects of yellow rust epidemics on the yield of winter wheat. Eur. J. Agron. 7:5362.

8. Chang, T. T., Konzak, C. F., and Zadoks, J. C. 1974. A decimal code for the growth stages of cereals. Weed Res. 14:415-421.

9. Cunniffe, N. J., Stutt, R. O. J. H., van den Bosch, F., and Gilligan, C. A. 2012. Time-dependent infectivity and flexible latent and infectious periods in compartmental models of plant disease. Phytopathology 102:365-380.

10. Eyal, Z. 1971. Kinetics of pycnospore liberation in Septoria tritici. Can. J. Bot. 49:1095-1099.

11. Garau, V. L., de Melo Abreu, S., Caboni, P., Angioni, A., Alves, A., and Cabras, P. 2009. Residue-free wines: Fate of some quinone outside inhibitor (QoI) fungicides in the winemaking process. J. Agric. Food Chem. 57:2329-2333.

12. Hanafi, A., Garau, V. L., Caboni, P., Sarais, G., and Cabras, P. 2010. Minor crops for export: A case study of boscalid, pyraclostrobin, lufenuron and lambda-cyhalothrin residue levels on green beans and spring onions in Egypt. J. Environ. Sci. Health Part B 45:493-500.

13. Hobbelen, P. H. F., Paveley, N. D., Fraaije, B. A., Lucas, J. A., and van den Bosch, F. 2011. Derivation and testing of a model to predict selection for fungicide resistance. Plant Pathol. 60:304-313.

14. Hobbelen, P. H. F., Paveley, N. D., Oliver, R. P., and van den Bosch, F. 2013. The usefulness of fungicide mixtures and alternation for delaying the selection for resistance in populations of Mycosphaerella graminicola on winter wheat: A modeling analysis. Phytopathology 103:690-707.

15. Hobbelen, P. H. F., Paveley, N. D., and van den Bosch, F. 2011. Delaying selection for fungicide insensitivity by mixing fungicides at a low and high risk of resistance development: A mode analysis. Phytopathology 101:1224-1233.

16. Hosoi, F., Nakai, Y., and Omasa, K. 2009. Estimating the leaf inclination angle distribution of the wheat canopy using a portable scanning lidar. J. Agric. Meteorol. 65:297-302.

17. Jamieson, P. D., Semenov, M. A., Brooking, I. R., and Francis, G. S. 1998. Sirius: A mechanistic model of wheat response to environmental variation. Eur. J. Agron. 8:161-179. 
18. Jarroudi, M. E., Delfosse, P., Maraite, H., Hoffmann, L., and Tychon, B. 2009. Assessing the accuracy of simulation model for Septoria leaf blotch disease progress on winter wheat. Plant Dis. 93:983-992.

19. Kildea, S., Dunne, B., Mullins, E., Cooke, L. R., Mercer, P. C., and O'Sullivan, E. 2010. Pyraclostrobin reduces germ tube growth of QoIresistant Mycosphaerella graminicola pycnidiospores and the severity of Septoria tritici blotch on winter wheat. Plant Pathol. 59:1091-1098.

20. Lawless, C., Semenov, M. A., and Jamieson, P. D. 2005. A wheat canopy model linking leaf area and phenology. Eur. J. Agron. 22:19-32.

21. Lockley, D., and Clark, W. S. 2005. Fungicide dose-response trials in wheat: The basis for choosing 'appropriate dose'. Pages 1-117 in: Project Rep. 373. HGCA.

22. Lovell, D. J., Hunter, T., Powers, S. J., Parker, S. R., and van den Bosch, F. 2004. Effect of temperature on latent period of Septoria leaf blotch on winter wheat under outdoor conditions. Plant Pathol. 53:170-181.

23. Lovell, D. J., Parker, S. R., Hunter, T., Welham, S. J., and Nichols, A. R. 2004. Position of inoculum in the canopy affects the risk of Septoria tritici blotch epidemics in winter wheat. Plant Pathol. 53:11-21.

24. Milne, A., Paveley, N. D., Audsley, E., and Livermore, P. 2003. A wheat canopy model for use in disease management decision support systems. Ann. Appl. Biol. 143:265-274.

25. Milne, A., Paveley, N. D., Audsley, E., and Parsons, D. 2007. A model of the effect of fungicides on disease-induced yield loss, for use in wheat disease management decision support systems. Ann. Appl. Biol. 151:113125.

26. O'Callaghan, J. R., Dahab, M. H., Hossain, A. H. M. S., and Wyseure, G. C. L. 1994. Simulation of Septoria tritici-winter wheat interactions. Comput. Electron. Agric. 11:309-321.

27. Paveley, N., Blake, J., Gladders, P., and Cockerell, V. 2012. Pages 1-32 in: HGCA Wheat Disease Management Guide. E. Boys, ed. Home Grown Cereals Authority, Warwick.

28. Paveley, N. D., Lockley, D., Vaughan, T. B., Thomas, J., and Schmidt, K. 2000. Predicting effective fungicide doses through observation of leaf emergence. Plant Pathol. 49:748-766.

29. Shaw, M. W. 1987. Assessment of upward movement of splash using a fluorescent tracer method and its application to the epidemiology of cereal pathogens. Plant Pathol. 36:201-213.

30. Shaw, M. W., and Royle, D. J. 1993. Factors determining the severity of epidemics of Mycosphaerella graminicola (Septoria tritici) on winter wheat in the UK. Plant Pathol. 42:882-899.

31. te Beest, D. E., Paveley, N., Shaw, M. W., and van den Bosch, F. 2013. Accounting for the economic risk caused by variation in disease severity in fungicide dose decisions, exemplified for Mycosphaerella graminicola on winter wheat. Phytopathology 103:666-672.

32. te Beest, D. E., Shaw, M. W., Paveley, N. D., and van den Bosch, F. 2009. Evaluation of a predictive model for Mycosphaerella graminicola for economic and environmental benefits. Plant Pathol. 58:1001-1009.

33. te Beest, D. E., Shaw, M. W., Pietravalle, S., and van den Bosch, F. 2009. A predictive model for early-warning of Septoria leaf blotch on winter wheat. Eur. J. Plant. Pathol. 124:413-425.

34. Thornley, J. H. M., and Johnson, I. R. 1990. Plant and Crop Modelling. Clarendon Press, Oxford.

35. van den Bosch, F., and Gilligan, C. A. 2008. Models of fungicide resistance dynamics. Annu. Rev. Phytopathol. 46:123-147.

36. van den Bosch, F., Paveley, N. D., Shaw, M. W., Hobbelen, P. H. F., and Oliver, R. 2011. The dose rate debate: Does the risk of fungicide resistance increase or decrease with dose? Plant Pathol. 60:597-606.

37. Waggoner, P. E., and Berger, R. D. 1987. Defoliation, disease, and growth. Phytopathology 77:393-398.

38. Womach, J. 2005. Agriculture: A Glossary of Terms, Programs, and Laws. Congressional Research Service, The Library of Congress.

39. Young, C. S., Thomas, J. M., Parker, S. R., and Paveley, N. D. 2006 Relationship between leaf emergence and optimum spray timing for leaf blotch (Rhynchosporium secalis) control on winter barley. Plant Pathol. 55:413-420.

40. Zhang, X. Y., Loyce, C., Meynard, J. M., and Monod, H. 2007. Modelling the effect of cultivar resistance on yield losses of winter wheat in natural multiple disease conditions. Eur. J. Agron. 26:384-393.

41. Zlof, V., and Sunley, R. 2011. Report of the EPPO workshop on azole fungicides and Septoria leaf blotch control. EPPO Bull. 41:145-148. 